\title{
Central release of nitric oxide mediates antinociception induced by aerobic exercise
}

\author{
G.S. Galdino ${ }^{1}$, I.D. Duarte ${ }^{2}$ and A.C. Perez ${ }^{2}$ \\ ${ }^{1}$ Curso de Fisioterapia, Escola de Enfermagem, Universidade Federal de Alfenas, Alfenas, MG, Brasil \\ ${ }^{2}$ Departamento de Farmacologia, Instituto de Ciências Biológicas, \\ Universidade Federal de Minas Gerais, Belo Horizonte, MG, Brasil
}

\begin{abstract}
Nitric oxide (NO) is a soluble gas that participates in important functions of the central nervous system, such as cognitive function, maintenance of synaptic plasticity for the control of sleep, appetite, body temperature, neurosecretion, and antinociception. Furthermore, during exercise large amounts of NO are released that contribute to maintaining body homeostasis. Besides NO production, physical exercise has been shown to induce antinociception. Thus, the present study aimed to investigate the central involvement of $\mathrm{NO}$ in exercise-induced antinociception. In both mechanical and thermal nociceptive tests, central [intrathecal (it) and intracerebroventricular (icv)] pretreatment with inhibitors of the NO/cGMP/K pathway (L-NOArg, ODQ, and glybenclamide) prevented the antinociceptive effect induced by aerobic exercise (AE). Furthermore, pretreatment (it, icv) with specific NO synthase inhibitors (L-NIO, aminoguanidine, and L-NPA) also prevented this effect. Supporting the hypothesis of the central involvement of NO in exercise-induced antinociception, nitrite levels in the cerebrospinal fluid increased immediately after AE. Therefore, the present study suggests that, during exercise, the NO released centrally induced antinociception.
\end{abstract}

Key words: Nitric oxide; Exercise; Pain; Antinociception

\section{Introduction}

Nitric oxide (NO) is a soluble gas continuously synthesized from the amino acid L-arginine in endothelial cells by the constitutive calcium calmodulin-dependent enzyme nitric oxide synthase (NOS) (1). A family of enzymes known as NOS catalyzes this reaction. There are two constitutive forms of the enzyme, neuronal NOS (nNOS) and endothelial NOS (eNOS), and an inducible form, inducible NOS (iNOS) (2). The presence of NOS in the brain was later confirmed (3), this enzyme was subsequently purified (4), and its cDNA was cloned and sequenced (5). Today, it is known that, in the central nervous system (CNS), NO production is associated with cognitive function, its role extending from the induction and maintenance of synaptic plasticity to sleep control, appetite, body temperature, and neurosecretion (6).

In addition to these functions, since the early 1990s studies have demonstrated that NO produces analgesia (7). The first studies showed that the antinociception induced by acetylcholine (ACh) is mediated by the release of NO (7). The antinociceptive effect produced by ACh was blocked by an inhibitor of the formation of NO from L-arginine $\left[\mathrm{N}^{\mathrm{G}}\right.$-monomethyl-L-arginine (L-NMMA)] and by methylene blue, an inhibitor of guanylate cyclase (7). Thus, these authors found that an intracellular signaling pathway participates in the analgesia produced by NO.

At the spinal level, $\mathrm{NO}$ is concentrated in the dorsal horn of the spinal cord, derived from diverse sources (including glial cells), and it has a definite role in spinal cord circuits (8). Additionally, it has been demonstrated that this neurotransmitter participates at a central level in antinociception via different antinociceptive agents (9).

Lorenzetti and Ferreira (10) found that NO participates in dipyrone-mediated antinociception at the spinal level. These authors have demonstrated that intraplantar administration of L-NMMA abolished the antinociception produced by dipyrone (intraplantar) in rats (10). At the supraspinal level, Tesser-Viscaíno et al. (11), in a model of temporomandibular joint arthritis, demonstrated that NO from nNOS spinal trigeminal neurons plays a role in antinociception. Basal NO concentrations have been shown to reduce the release of $\gamma$-aminobutyric acid (GABA) in a $\mathrm{Ca}^{2+}$ and $\mathrm{Na}^{+}$dependent manner, while high levels of $\mathrm{NO}$ increase the release of GABA, an important neurotransmitter involved in pain control (9). However, high levels of NO are responsible for increasing levels of reactive nitrogen

Correspondence: G.S. Galdino: <giovanegsouza@yahoo.com.br>.

Received May 31, 2014. Accepted October 6, 2014. First published online December 19, 2014. 
oxide species and reactive oxygen species, which can contribute to an indiscriminate impairment of the structural and functional integrity of cells, and modification of cellular DNA, proteins, and lipids in the brain (12).

Physical exercise is another physiological inductor of NO production. During exercise, the increase in shear stress caused by increasing blood flow and muscle contraction-induced distortion of resistance vessels stimulates eNOS and nNOS (13). Furthermore, microdamage to myofibrils during muscle contractions releases and/or stimulates inflammatory cells, activating iNOS. Red blood cells release ATP in low-oxygen environments and by the deformation caused by muscle contractions. Thus, ATP binds to purinergic receptors on the endothelium, leading to eNOS activation and consequently to NO production (14).

Additionally, recent work by our group demonstrated an involvement of the $\mathrm{NO} / \mathrm{CGMP}_{\mathrm{K}} \mathrm{K}_{\mathrm{ATP}}$ pathway in peripheral antinociception induced by exercise (15). Exercise-induced analgesia has been demonstrated since the early 1980s (16). However, few central endogenous systems have been described involved in this effect, although recent studies demonstrated the participation of the noradrenergic and endocannabinoid systems $(17,18)$.

Even though several studies have demonstrated the importance of $\mathrm{NO}$ in exercise physiology, none have evaluated its central participation. Furthermore, a study would be important that evaluated the involvement of this neurotransmitter in the antinociceptive effect induced by exercise at the central level, whereas NO is released in different areas of the brain and spinal cord (12). Thus, the present study aimed to investigate the central participation of $\mathrm{NO}$ in the antinociception induced by aerobic exercise $(A E)$, which can lead to future clinical and experimental studies about mechanisms involved in pain control by non-pharmacological treatments.

\section{Material and Methods}

\section{Animals}

The experiments were performed with male Wistar rats weighing 180-200 g obtained from CEBIO-UFMGBrazil. The rats were housed in a temperature-controlled room $\left(23 \pm 1^{\circ} \mathrm{C}\right)$ on an automatic 12:12-h light-dark cycle (6:00 am to $6: 00 \mathrm{pm})$. All tests occurred during the light phase (8:00 am to 4:00 pm). Food and water were freely available until the onset of the experiments. The Ethics Committee on Animal Experimentation of the Universidade Federal de Minas Gerais (protocol \#185/ 2007) approved the study, and all experiments followed the guidelines of the International Association for the Study of Pain on the use of laboratory animals.

\section{Drugs}

The drugs used were N-nitro-L-arginine (L-NOArg; Sigma, USA), an unspecific NOS inhibitor; aminoguanidine (AMG, Sigma), an iNOS inhibitor; $N^{5}$-(1-iminoethyl)-L-ornithine dihydrochloride (L-NIO; Sigma), an eNOS inhibitor; and $\mathrm{N \omega}$ propyl-L-arginine (L-NPA; Cayman, USA), an nNOS inhibitor, all diluted in physiological saline solution $(0.9 \% \mathrm{NaCl})$; and $1 \mathrm{H}-$ $(1,2,4)$ oxidiazolo[4,3-a]quinoxalin-1-one (ODQ; Tocris, USA), a guanylyl cyclase inhibitor, diluted in DMSO $(10 \%$ in saline solution); and glibenclamide (GLB; Sigma), a K $\mathrm{K}_{\text {ATP }}$ channel blocker, diluted in Tween (1\% in saline solution). The control group received the same volume of physiological saline or vehicle in the same area as the experimental groups. The concentrations of drugs were selected according to a doseresponse curve (data not shown).

\section{Injections}

Intrathecal injection. The intrathecal injections (it) were performed in a volume of $10 \mu \mathrm{L}$ in the subarachnoid space between L5 and L6 using a $30 \mathrm{G} \times 1 / 2$-inch needle and a $50-\mu \mathrm{L}$ precision syringe (Hamilton Company, USA) (19). Intrathecal injection is stressful for rats and, according to the International Association for the Study of Pain (IASP) recommendations, requires anesthesia. Thus, before injection, rats were slightly anesthetized with volatile isoflurane $(3.5 \%)$ and recovered $5 \mathrm{~min}$ after removal from the anesthesia chamber. Correct it positioning of the needle tip was confirmed by a characteristic tail-flick response in the animal. Lidocaine $(4 \%, 10 \mu \mathrm{L})$ was administered to a group of test animals, using temporary paralysis of the hind limbs as an endpoint to confirm the effectiveness of the injection technique. Intrathecal injections were administered immediately prior to exercise.

Intracerebroventricular injection. Initially before intracerebroventricular (icv) injections (20), each rat was anesthetized with a mixture of ketamine $(80 \mathrm{mg} / \mathrm{kg})$ and xylazine $(10 \mathrm{mg} / \mathrm{kg})$ injected $i p$, and then placed in a stereotaxic apparatus (Stoelting, USA). The scalp was incised, and the skull was leveled off around the bregma. A 22-gauge, 12-mm stainless-steel guide cannula was inserted into the right lateral ventricle of the brain. The cannula aimed for the following coordinates: $1.5 \mathrm{~mm}$ posterior to the bregma, $2.5 \mathrm{~mm}$ lateral to the midline, and $3.3 \mathrm{~mm}$ below the top of the skull (21). The skull was fixed to the cannula using three screws and acrylic dental floss. A $12.5-\mathrm{mm}$ stylet was then inserted into the cannula to keep it patent before the injection. Animals had a 5-day recovery period before the experiments. For icv drug injections, a $12.5-\mathrm{mm}$ injection needle attached to a $30-\mathrm{cm}$ polyethylene tube fitted to a $10-\mu \mathrm{L}$ Hamilton syringe was used. Then, the stylet was withdrawn manually, and the injection needle was manually inserted into the guide cannula. The volume of solution injected into the lateral ventricle was $5 \mu \mathrm{L}$ over a period of $120 \mathrm{~s}$. Intracerebroventricular injections were performed immediately prior to exercise.

\section{Exercise}

Acute $A E$ was performed using a rodent treadmill. Animals ran with a progressive speed of $20 \mathrm{~m} / \mathrm{min}$ and $0 \%$ inclination, for an average time of $45.03 \pm 2 \mathrm{~min}$, until 
fatigue (15). Fatigue was defined as the point at which the animals were unable to keep pace with the treadmill. The back of the treadmill had an electrical stimulator $(3 \mathrm{~V})$ to encourage the animals to run. To familiarize the rats to exercise, thereby reducing the effects of stress, they were run daily on the treadmill.

The groups were as follows ( $\mathrm{N}=6$ per group): control (Co), animals that did not perform exercise and received saline; acute $A E(A E)$, animals that ran and received saline; $A E+L-N O A r g$, animals pretreated with unspecific NOS inhibitor that exercised; $A E+O D Q$, animals pretreated with guanylyl cyclase inhibitor that exercised; $A E+G L B$, animals pretreated with $\mathrm{K}_{\mathrm{ATP}}$ channel blocker irreversible (glibenclamide) that exercised; $\mathrm{AE}+\mathrm{AMG}$, animals pretreated with iNOS inhibitor (aminoguanidine) that exercised; $\mathrm{AE}+\mathrm{L}-\mathrm{NIO}$, animals pretreated with eNOS inhibitor; and $\mathrm{AE}+\mathrm{L}-\mathrm{NPA}$, animals pretreated with nNOS inhibitor. Different groups of animals received the drugs via it and $i c v$ administration. In each route of administration (it or icv), the control group was the same in the experiments performed with unspecific or specific inhibitors of the NO/ $\mathrm{CGMP} / \mathrm{K}_{\mathrm{ATP}}$ pathway. One group received the same quantity of electrical stimulation as the $A E$ group, and there was no change to the nociceptive threshold.

\section{Paw-withdrawal test}

An apparatus (Ugo Basile, Italy) was used to evaluate a response to mechanical nociceptive stimuli at central and peripheral levels. A cone-shaped pusher with a rounded tip (base diameter $=9 \mathrm{~mm}$ ) was applied to the plantar surface of the animal's paw. The frequency of force application was set at $150-160 \mathrm{~g} / \mathrm{s}$, and there was a $240 \mathrm{~g} / \mathrm{s}$ loading cutoff to avoid damaging the tissue. The intensity of pressure causing an escape reaction was defined as the withdrawal threshold (22).

\section{Tail-flick test}

Animals were placed on the tail-flick apparatus (Ugo Basile), which allows collection of information on the mechanism and location of the antinociceptive activity detected, since the tail-flick reflex is spinally integrated (23). In this apparatus, the animal's tail is smoothed into a groove that contains a photocell. A light source was activated and the light remained focused on the tail until the rat moved its tail (a spinal reflex), thereby switching the light off. The intensity of the light was adjusted to obtain a baseline tail-flick latency of 2-4 s, and a cutoff time of $9 \mathrm{~s}$ was chosen to prevent tissue damage (23).

\section{Cerebrospinal fluid (CSF) collection}

CSF was collected while the rats were under anesthesia with $2 \%$ isoflurane by puncture between the occipital protuberance and the spinal atlas into the cisterna magna with a 30 -gauge needle $(13 \times 3$ in) (24). The material was centrifuged for $5 \mathrm{~min}(2839.2 \mathrm{~g})$ and stored in a freezer at $-80^{\circ} \mathrm{C}$. In the exercised group
$(A E), C S F$ and plasma were collected immediately after exercise.

\section{Nitrite determination}

Nitrite levels were measured using the Griess reaction (25). Briefly, $100 \mu \mathrm{L}$ of the homogenate was applied to a microliter plate well, followed by $100 \mu \mathrm{L}$ of Griess reagent $[0.2 \%(\mathrm{w} / \mathrm{v})$ naphthylene ethylenediamine and $2 \%(\mathrm{w} / \mathrm{v})$ sulfanilamide in $5 \%(\mathrm{v} / \mathrm{v})$ phosphoric acid]. After $10 \mathrm{~min}$ of color development at room temperature, the absorbance was measured with a microplate reader (Titertek Multiskan MCC/340; Flow Laboratories, USA) at a wavelength of $545 \mathrm{~nm}$. Each sample was assayed in duplicate wells. The nitrite standard reference curves were made with sodium nitrite in distilled water at concentrations of $100,50,25$, $12.5,6.25,3.13$, and $1.56 \mu \mathrm{M}$. The detection limit of the assay was $\sim 1.5 \mu \mathrm{mol} / \mathrm{L}$ in distilled water.

\section{Statistical analysis}

Data are reported as means \pm SE of the evaluated parameter and were analyzed for statistical significance by one-way ANOVA followed by the Bonferroni post hoc test for multiple comparisons. Comparisons between two groups ( $t$-test) were used for results obtained by nitrite determination. The minimum level of significance was considered to be $\mathrm{P}<0.05$. Statistical analyses and preparation of figures were performed using the GraphPad Prism software, version 4 (USA).

\section{Results}

Immediately after $A E$, the nociceptive threshold of rats was increased $(P<0.05)$ for more than $15 \mathrm{~min}$ in both paw-withdrawal and tail-flick nociceptive tests (Figures 1, 2, and 3). The increase was prevented $(P<0.001)$ by inhibitors of the $\mathrm{NO} / \mathrm{cGMP} / \mathrm{K}_{\mathrm{ATP}}$ pathway, the unspecific NOS inhibitors, L-NOArg $(50 \mu \mathrm{g} / 10 \mu \mathrm{L})$, ODQ $(4 \mu \mathrm{g} / 10 \mu \mathrm{L})$, and GLB $(10 \mu \mathrm{g} / 10 \mu \mathrm{L})$, preinjected it (Figure $1 \mathrm{~A}$ and $\mathrm{B}$ ). Furthermore, preinjection it of specific NOS inhibitors, L-NIO, AMG, and L-NPA, also significantly $(P<0.001)$ prevented exercise-induced antinociception in both paw-withdrawal and tail-flick tests (Figure 2A and $B$ ).

Additionally, to confirm the supraspinal involvement of the $\mathrm{NO} / \mathrm{cGMP} / \mathrm{K}_{\mathrm{ATP}}$ pathway, the same inhibitors were injected $i c v$. Figure $3 A$ and $B$ shows that preinjection of $\mathrm{NO} / \mathrm{cGMP} / \mathrm{K}_{\text {ATP }}$ pathway inhibitors L-NOArg $(10 \mu \mathrm{g} / 5 \mu \mathrm{L})$, ODQ $(10 \mu \mathrm{g} / 5 \mu \mathrm{L})$, and GLB $(10 \mu \mathrm{g} / 5 \mu \mathrm{L})$ prevented $(P<0.001)$ the antinociceptive effect produced by $A E$ in the paw-withdrawal and tail-flick tests. Similar to results found with the drugs administered it, the specific NOS inhibitors L-NIO, AMG, and L-NPA also prevented $(P<0.001)$ exercise-induced antinociception in both nociceptive tests (Figure $4 A$ and $B$ ).

Furthermore, the nitrite levels in CSF were significantly $(P<0.01)$ increased immediately after AE (Figure 5), 

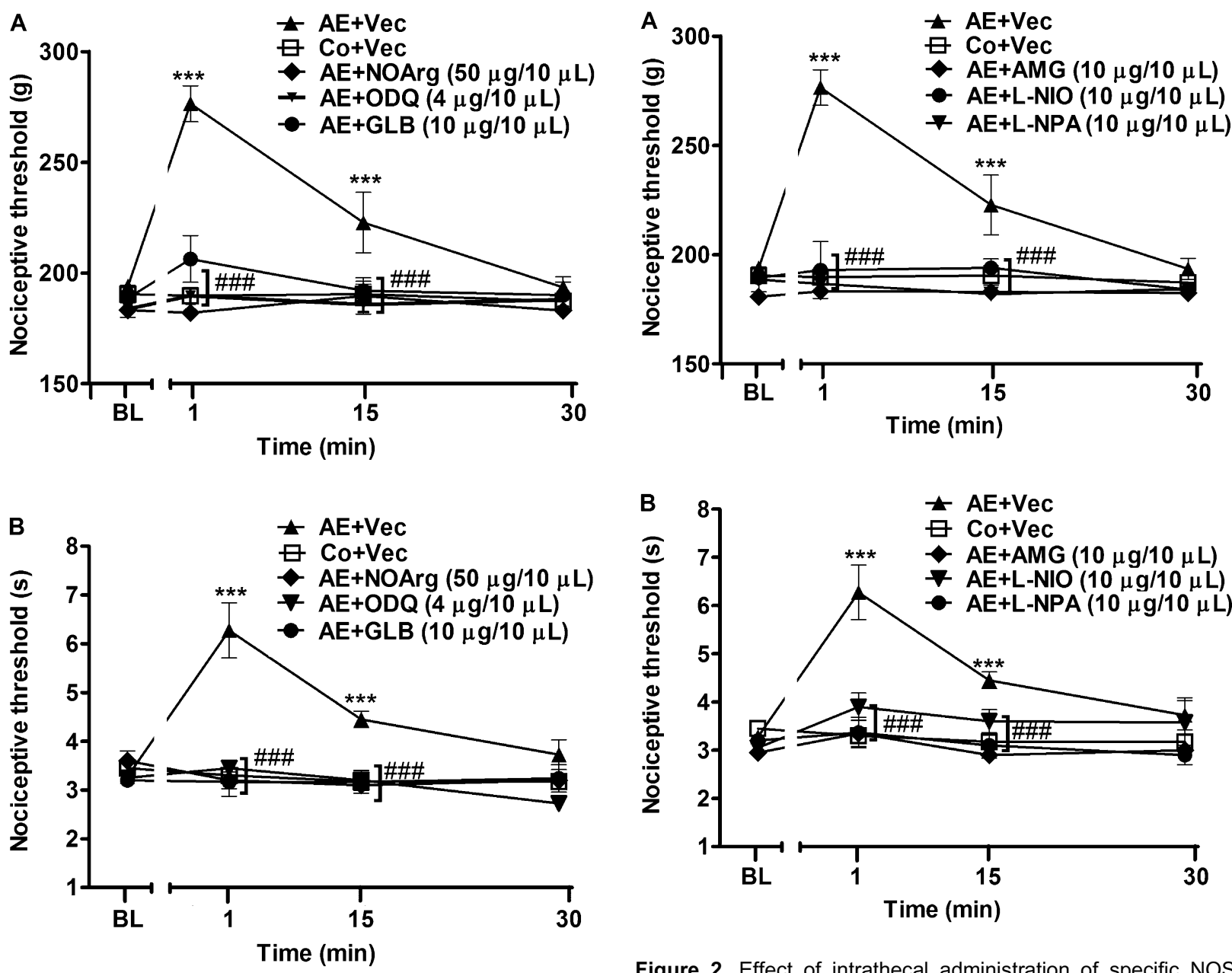

Figure 1. Effect of intrathecal administration of nitric oxide/ cGMP/K $/ K_{\text {ATP }}$ pathway inhibitors on the antinociception induced by acute aerobic exercise (AE) in the paw-withdrawal $(A)$ and tailflick $(B)$ tests. Rats were pretreated with intrathecal injection of $N$-nitro-L-arginine (L-NOArg, $50 \mu \mathrm{g} / 10 \mu \mathrm{L}), 1 \mathrm{H}-(1,2,4)$ oxidiazolo[4,3-a]quinoxalin-1-one (ODQ, $4 \mu \mathrm{g} / 10 \mu \mathrm{L}$ ), and glibenclamide $(\mathrm{GLB}, 10 \mu \mathrm{g} / 10 \mu \mathrm{L})$ immediately before the onset of $A E$, which lasted for a mean of $45.3 \pm 2.0 \mathrm{~min}$. Mechanical and thermal nociceptive thresholds were measured before and after $1,15,30$ min of $A E$. Data are reported as means \pm SE of 6 animals per group. ${ }^{* *} \mathrm{P}<0.001$, compared to the control group (Co); \#\#\# $\mathrm{P}<0.001$, compared to the AE group (one-way ANOVA followed by the Bonferroni test). Vec: vehicle; BL: baseline latency.

supporting the hypothesis that the NO released centrally during exercise takes part in the antinociception.

\section{Discussion}

The present study found that the NO/cGMP/ $\mathrm{K}_{\text {ATP }}$ pathway possibly participates in exercise-induced antinociception at both spinal and supraspinal levels.

Figure 2. Effect of intrathecal administration of specific NOS inhibitors on the antinociception induced by acute aerobic exercise $(\mathrm{AE})$ in the paw-withdrawal $(A)$ and tail-flick $(B)$ tests. Rats were pretreated with intrathecal injection of aminoguanidine (AMG, $10 \mu \mathrm{g} / 10 \mu \mathrm{L}$ ), $N^{5}$-(1-iminoethyl)-L-ornithine dihydrochloride $(\mathrm{L}-\mathrm{NIO}, 10 \mu \mathrm{g} / 10 \mu \mathrm{L}$ ) and $N \omega$-propyl-L-arginine (L-NPA, $10 \mu \mathrm{g} / 10 \mu \mathrm{L}$ ) immediately before the onset of exercise, which lasted for a mean of $42.2 \pm 4.0 \mathrm{~min}$. Mechanical and thermal nociceptive thresholds were measured before and after 1, 15, $30 \mathrm{~min}$ of $A E$. Data are reported as means $\pm S E$ of 6 animals per group. ${ }^{* *} \mathrm{P}<0.001$, compared to the control group (Co); $\# \# \# P<0.001$, compared to the $A E$ group (one-way ANOVA followed by the Bonferroni test). Vec: vehicle; BL: baseline latency.

Studies have demonstrated the involvement of endogenous mechanisms involved in this effect (16). However, most of the studies evaluated the peripheral influence of these mechanisms in exercise-induced analgesia. Only two studies demonstrated the participation of endogenous substances in this effect at the central level $(17,18)$. These studies reported a reversion of the antinociceptive effect produced by exercise after it and icv administration of noradrenergic and cannabinoid receptor antagonists. Furthermore, those authors demonstrated that, after 

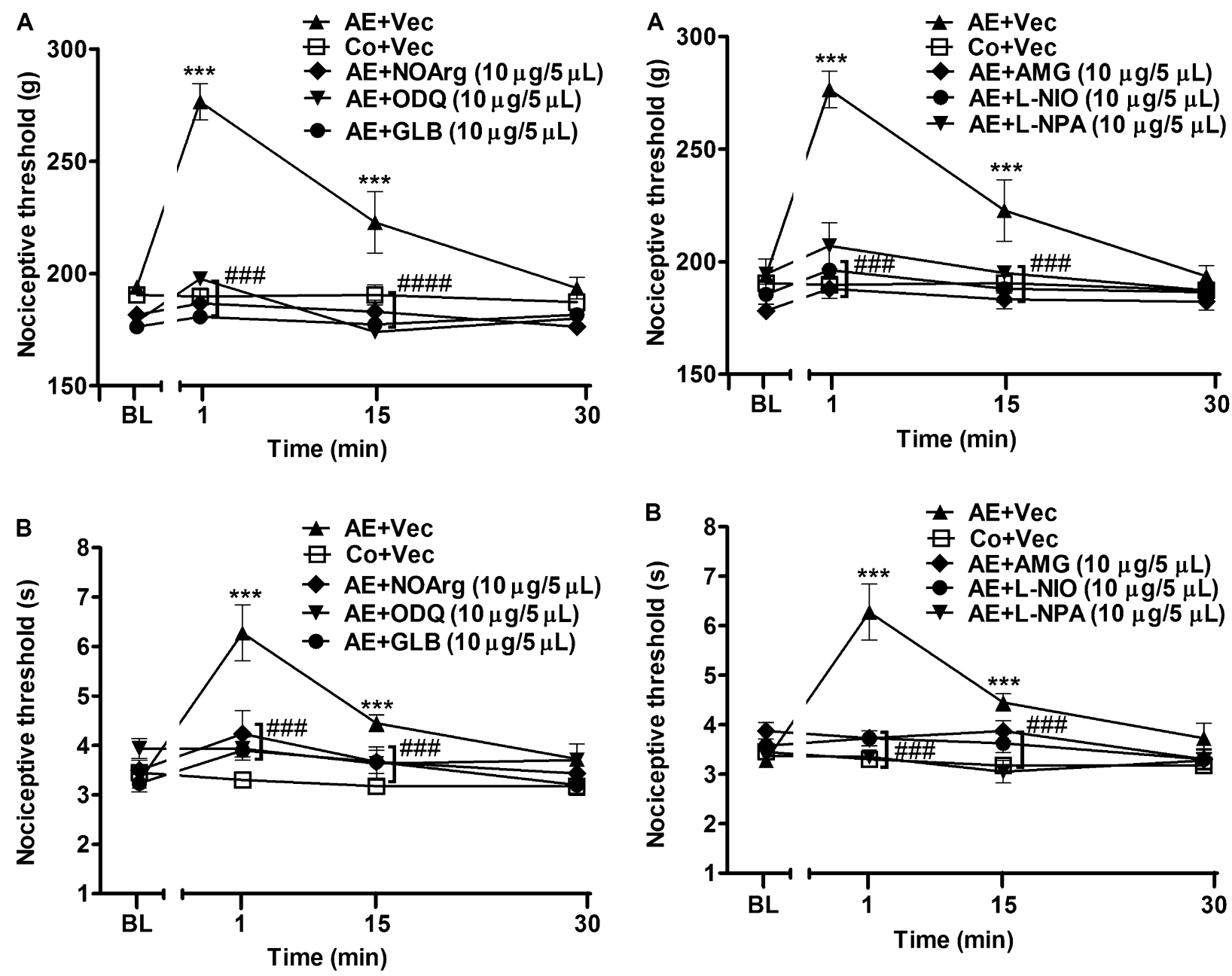

Figure 3. Effect of intracerebroventricular administration of nitric oxide/cGMP/K $/ \mathrm{KTP}_{\mathrm{AT}}$ pathway inhibitors on the antinociception induced by acute aerobic exercise (AE) in the paw-withdrawal $(A)$ and tail-flick $(B)$ tests. Rats were pretreated with intracerebroventricular injection of $N$-nitro-L-arginine (L-NOArg, $10 \mu \mathrm{g} /$ $5 \mu \mathrm{L}), \mathrm{H}-(1,2,4)$ oxidiazolo[4,3-a]quinoxalin-1-one (ODQ, $10 \mu \mathrm{g} /$ $5 \mu \mathrm{L}$ ) and glibenclamide (GLB, $10 \mu \mathrm{g} / 5 \mu \mathrm{L}$ ) immediately before the onset of exercise, which lasted for a mean of $44.2 \pm 1.5 \mathrm{~min}$. Mechanical and thermal nociceptive thresholds were measured before and after 1, 15, $30 \mathrm{~min}$ of $\mathrm{AE}$. Data are reported as means $\pm S E$ of 6 animals per group. ${ }^{* * *} \mathrm{P}<0.001$, compared to the control group (Co); \#\#\#P<0.001, compared to the $A E$ group (one-way ANOVA followed by the Bonferroni test). Vec: vehicle; BL: baseline latency.

exercise, there was an increase in noradrenergic and cannabinoid receptor expression.

According to our previous studies and evidence in the literature that demonstrated a correlation of both systems (noradrenergic and endocannabinoid) with NO, our group aimed to investigate the central involvement of the NO/cGMP/K $\mathrm{K}_{\mathrm{ATP}}$ pathway in this effect. In

Figure 4. Effect of intracerebroventricular administration of specific NOS inhibitors on the antinociception induced by acute aerobic exercise $(\mathrm{AE})$ in the paw-withdrawal $(A)$ and tail-flick $(B)$ tests. Rats were pretreated with intracerebroventricular injection of aminoguanidine (AMG, $10 \mu \mathrm{g} / 5 \mu \mathrm{L}$ ), $N^{5}$-(1iminoethyl)-L-ornithine dihydrochloride (L-NIO, $10 \mu \mathrm{g} / 5 \mu \mathrm{L}$ ) and $N \omega$-propyl-L-arginine (L-NPA, $10 \mu \mathrm{g} / 5 \mu \mathrm{L}$ ) immediately before the onset of exercise, which lasted for a mean of $43.3 \pm 1.0 \mathrm{~min}$. Mechanical and thermal nociceptive thresholds were measured before and after 1, 15, $30 \mathrm{~min}$ of $\mathrm{AE}$. Data are reported as means \pm SE of 6 animals per group. ${ }^{* * *} P<0.001$, compared to the control group (Co); $\# \# \# P<0.001$, compared to the $A E$ group (one-way ANOVA followed by the Bonferroni test). Vec: vehicle; BL: baseline latency.

support of this, Romero et al. (26) showed that the antinociception produced by endocannabinoid $N$-palmitoyl-ethanolamine was antagonized by specific inhibitors of the NO/cGMP pathway. In addition to this, NO is known to react with norepinephrine in vivo in the brain to form 6-nitro-norepinephrine, which inhibits neuronal norepinephrine reuptake. A study corroborating this 


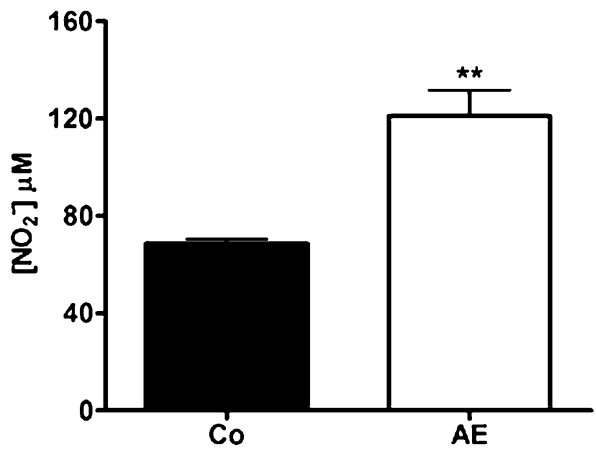

Figure 5. Effect of acute aerobic exercise (AE) on nitrite $\left[\mathrm{NO}_{2}\right]$ cerebrospinal fluid (CSF) levels. Immediately after AE (open bar), the cerebrospinal fluid levels were increased compared to the control group (Co, shaded bar). Data are reported as means $\pm \mathrm{SE}$ of 5 animals per group. ${ }^{* *} \mathrm{P}<0.01$, compared to Co (nonexercised rats) (t-test).

found that it injection of 6-nitro-norepinephrine produced antinociception and interacted additively with norepinephrine in this effect, suggesting a functional interaction between spinal NO and norepinephrine in analgesia (27). Furthermore, it has been reported that NO also increases the release of norepinephrine in various brain areas (28). Although it was not the aim of our study, NO may be activated by both systems previously described, during exercise.

The results presented in this study demonstrated that the three forms of NOS (nNOS, eNOS, and iNOS) participated in the antinociceptive mechanism. When preadministered it, the antagonists of the three forms of NOS reversed the antinociceptive effect produced by exercise, supporting our hypothesis involving both forms in this effect. Other research has shown that NO donors inhibited spontaneously activated neurons in the superficial dorsal horn of rats (29) and diminished evoked substance $P$ and calcitonin gene-related peptide released in spinal cord slices in vitro, effects that are consistent with analgesic actions (30). In addition, NOS has been identified in glial cells, interneurons, and fibers in the spinal cord (31). In support of this, several factors are responsible for the increase in NO production during resistance exercise. In rodent skeletal muscle, nNOS, eNOS, and iNOS isoforms are highly expressed within muscle fibers and activated by exercise. The increase in shear stress caused by increased blood flow and muscle contraction-induced distortion of resistance vessels stimulates eNOS and nNOS (13). In addition, microdamage in the myofibrils during muscle contractions releases and stimulates inflammatory cells that will activate iNOS present in red blood cells, which will release ATP in lowoxygen environments and in response to deformation of muscle during contractions. Then, ATP binds to purinergic receptors on the endothelium, leading to eNOS activation and NO production (14). Furthermore, nNOS and eNOS transcription and expression were found to be increased in human skeletal muscle after exercise (32). Additionally, it was reported that exercise induces nNOS, eNOS, and iNOS expression in the CNS (33). Thus, the NO release during exercise may happen systemically, inclusive at the central level.

Our results also showed that the three NO isoforms participated in exercise-induced antinociception at the supraspinal level, after a reversion of the antinociceptive effect by preadministration icv of specific inhibitors. In addition, studies have demonstrated that NO has a complex and diverse role in the modulation of nociceptive processing at various levels of the neuraxis (34). A study reported that swimming for $2 \mathrm{~h}$ /day produced an increase in iNOS, eNOS, and nNOS expression in the hippocampus (35). NO has also been found in neurons in the periaqueductal grey matter (PAG), an important area of pain modulation. In addition, the dorsolateral and ventrolateral PAG contains a column of NOScontaining cells, which may release NO that could participate in the inhibitory modulation of pain (36). NO might also promote the release of serotonin, an important neurotransmitter involved in the inhibition of nociceptive impulses in the dorsal horn of the spinal cord (37). In accordance with the above, we suggest that the central antinociceptive effect produced by exercise occurred by activation of descending control of pain associated to NO activation and production. In addition, to support our results, an increase in nitrite levels in the CSF was found. Thus, we suggest that both NOS isoforms can be activated at the same intensity by the exercise protocol used.

NO may stimulate guanylyl cyclase-coupled NO receptors in axons, leading to increasing cGMP levels in axons of the CNS (9). Our results showed that pretreatment with a cGMP inhibitor (ODQ) prevented the antinociception induced by exercise.

$\mathrm{K}_{\text {ATP }}$ channels play an important role in supraspinal, spinal, and peripheral antinociception. The opening of these channels for openers (monoxidil, metamizol, and opioids agonists) elucidated antinociception (38). In addition, $\mathrm{K}_{\text {ATP }}$ channels are on the surface membranes and mitochondria of many different cell types involved in exercise, including pancreatic $\beta$-cells, neurons, cardiac myocytes, skeletal, and smooth muscle cells (38). Furthermore, the $\mathrm{K}_{\text {ATP }}$ channel blocker glibenclamide reversed the antinociceptive effect of exercise. Similar to our results, morphine-induced antinociception in nondiabetic mice was antagonized by pretreatment with glibenclamide. Thus, we suggest that exercise may induce the expression of these channels in CNS areas that participate in pain modulation.

In conclusion, the results of this study indicated that the $\mathrm{NO} / \mathrm{cGMP} / \mathrm{K}_{\mathrm{ATP}}$ pathway participates in exerciseinduced antinociception at both spinal and supraspinal 
levels. Furthermore, it demonstrated that this effect involves the three isoforms of NOS. Thus, the present work is important to further studies on the endogenous mechanisms involved in the antinociceptive effect produced by exercise. Future studies will help unravel possible endogenous mechanisms involving

\section{References}

1. Mayer B, Hemmens B. Biosynthesis and action of nitric oxide in mammalian cells. Trends Biochem Sci 1997; 22: 477-481, doi: 10.1016/S0968-0004(97)01147-X.

2. Dominiczak AF, Bohr DF. Nitric oxide and its putative role in hypertension. Hypertension 1995; 25: 1202-1211, doi: 10.1161/ 01.HYP.25.6.1202.

3. Knowles RG, Palacios M, Palmer RM, Moncada S. Formation of nitric oxide from L-arginine in the central nervous system: a transduction mechanism for stimulation of the soluble guanylate cyclase. Proc Natl Acad Sci U S A 1989; 86: 5159-5162, doi: 10.1073/pnas.86.13.5159.

4. Bredt DS, Snyder SH. Isolation of nitric oxide synthetase, a calmodulin-requiring enzyme. Proc Natl Acad Sci U S A 1990; 87: 682-685, doi: 10.1073/pnas.87.2.682

5. Bredt DS, Hwang PM, Glatt CE, Lowenstein C, Reed RR, Snyder $\mathrm{SH}$. Cloned and expressed nitric oxide synthase structurally resembles cytochrome P-450 reductase. Nature 1991; 351: 714-718, doi: 10.1038/351714a0.

6. Guix FX, Uribesalgo I, Coma M, Munoz FJ. The physiology and pathophysiology of nitric oxide in the brain. Prog Neurobiol 2005; 76: 126-152, doi: 10.1016/j.pneurobio.20 05.06.001.

7. Cury Y, Picolo G, Gutierrez VP, Ferreira SH. Pain and analgesia: The dual effect of nitric oxide in the nociceptive system. Nitric Oxide 2011; 25: 243-254, doi: 10.1016/ j.niox.2011.06.004.

8. Freire MA, Guimaraes JS, Leal WG, Pereira A. Pain modulation by nitric oxide in the spinal cord. Front Neurosci 2009; 3: 175-181, doi: 10.3389/neuro.01.024.2009.

9. Calabrese V, Mancuso C, Calvani M, Rizzarelli E, Butterfield DA, Stella AM. Nitric oxide in the central nervous system: neuroprotection versus neurotoxicity. Nat Rev Neurosci 2007; 8: 766-775, doi: 10.1038/nrn2214.

10. Lorenzetti BB, Ferreira SH. Activation of the arginine-nitric oxide pathway in primary sensory neurons contributes to dipyrone-induced spinal and peripheral analgesia. Inflamm Res 1996; 45: 308-311, doi: 10.1007/BF02280997.

11. Tesser-Viscaíno SA, Denadai-Souza A, Teixeira SA, Ervolino E, Cruz-Rizzolo RJ, Costa SK, et al. Putative antinociceptive action of nitric oxide in the caudal part of the spinal trigeminal nucleus during chronic carrageenaninduced arthritis in the rat temporomandibular joint. Brain Res 2009; 1302: 85-96, doi: 10.1016/j.brainres.2009.09.056.

12. Förstermann U, Sessa WC. Nitric oxide synthases: regulation and function. Eur Heart J 2012; 33: 829-837, doi: 10.1093/eurheartj/ehr304.

13. McConell GK, Bradley SJ, Stephens TJ, Canny BJ, Kingwell BA, Lee-Young RS. Skeletal muscle nNOS mu protein content is increased by exercise training in humans. $A m ~ J$ Physiol Regul Integr Comp Physiol 2007; 293: R821-R828, doi: 10.1152/ajpregu.00796.2006. exercise-induced analgesia, which may aid in the clinical treatment of patients with different painful conditions.

\section{Acknowledgments}

\author{
Research supported by FAPEMIG and CNPq.
}

14. Tschakovsky ME, Joyner MJ. Nitric oxide and muscle blood flow in exercise. Appl Physiol Nutr Metab 2008; 33: 151-161, doi: $10.1139 / \mathrm{H} 07-148$

15. Galdino GS, Cortes SF, Duarte ID, Perez AC. Involvement of the nitric oxide/(C)GMP/K(ATP) pathway in antinociception induced by exercise in rats. Life Sci 2010; 86: 505-509, doi: 10.1016/j.lfs.2010.02.004.

16. Koltyn KF. Analgesia following exercise: a review. Sports Med 2000; 29: 85-98, doi: 10.2165/00007256-200029020-00002.

17. de Souza GG, Duarte ID, de Castro PA. Differential involvement of central and peripheral alpha2 adrenoreceptors in the antinociception induced by aerobic and resistance exercise. Anesth Analg 2013; 116: 703-711, doi: 10.1213/ANE.0b013e31827ab6e4

18. Galdino G, Romero TR, Silva JF, Aguiar DC, de Paula AM, Cruz JS, et al. The endocannabinoid system mediates aerobic exercise-induced antinociception in rats. Neuropharmacology 2014; 77: 313-324, doi: 10.1016/j.neuropharm. 2013.09.022.

19. Mestre C, Pelissier T, Fialip J, Wilcox G, Eschalier A. A method to perform direct transcutaneous intrathecal injection in rats. J Pharmacol Toxicol Methods 1994; 32: 197200, doi: 10.1016/1056-8719(94)90087-6.

20. Mahmoudi M, Zarrindast MR. Effect of intracerebroventricular injection of GABA receptor agents on morphineinduced antinociception in the formalin test. J Psychopharmacol 2002; 16: 85-91, doi: 10.1177/026988110201 600108.

21. Paxinos G, Watson $\mathrm{C}$. The rat brain in stereotaxic coordinates. Toronto: Academic Press; 1986.

22. Randall LO, Selitto JJ. A method for measurement of analgesic activity on inflamed tissue. Arch Int Pharmacodyn Ther 1957; 111: 409-419.

23. D'amour EF, Smith D. A method for determining loss of pain sensation. J Pharmacol Exp Ther 1941; 72: 74-79.

24. Green LC, Wagner DA, Glogowski J, Skipper PL, Wishnok JS, Tannenbaum SR. Analysis of nitrate, nitrite, and $\left[{ }^{15} \mathrm{~N}\right]$ nitrate in biological fluids. Anal Biochem 1982; 126: 131-138, doi: 10.1016/0003-2697(82)90118-X.

25. Nirogi R, Kandikere V, Mudigonda K, Bhyrapuneni G, Muddana N, Saralaya R, et al. A simple and rapid method to collect the cerebrospinal fluid of rats and its application for the assessment of drug penetration into the central nervous system. J Neurosci Methods 2009; 178: 116-119, doi: 10.1016/j.jneumeth.2008.12.001.

26. Romero TR, Galdino GS, Silva GC, Resende LC, Perez AC, Cortes SF, et al. Involvement of the L-arginine/nitric oxide/ cyclic guanosine monophosphate pathway in peripheral antinociception induced by $\mathrm{N}$-palmitoyl-ethanolamine in rats. J Neurosci Res 2012; 90: 1474-1479, doi: 10.1002/ jnr.22797. 
27. Chiari A, Li XH, Xu Z, Pan HL, Eisenach JC. Formation of 6-nitro-norepinephrine from nitric oxide and norepinephrine in the spinal cord and its role in spinal analgesia. Neuroscience 2000; 101: 189-196, doi: 10.1016/S03064522(00)00328-6.

28. Prast $\mathrm{H}$, Philippu A. Nitric oxide as modulator of neuronal function. Prog Neurobiol 2001; 64: 51-68, doi: 10.1016/ S0301-0082(00)00044-7.

29. Schmid HA, Pehl U. Regional specific effects of nitric oxide donors and CGMP on the electrical activity of neurons in the rat spinal cord. J Chem Neuroanat 1996; 10: 197-201, doi: 10.1016/0891-0618(96)00143-3.

30. Garry MG, Richardson JD, Hargreaves KM. Sodium nitroprusside evokes the release of immunoreactive calcitonin gene-related peptide and substance $P$ from dorsal horn slices via nitric oxide-dependent and nitric oxideindependent mechanisms. J Neurosci 1994; 14: 4329-4337.

31. Dun NJ, Dun SL, Wu SY, Forstermann U, Schmidt HH, Tseng LF. Nitric oxide synthase immunoreactivity in the rat, mouse, cat and squirrel monkey spinal cord. Neuroscience 1993; 54: 845-857, doi: 10.1016/0306-4522(93)90579-5.

32. Chavoshan B, Fournier M, Lewis MI, Porszasz J, Storer $\mathrm{TW}, \mathrm{Da} \mathrm{X}$, et al. Testosterone and resistance training effects on muscle nitric oxide synthase isoforms in COPD men. Respir Med 2012; 106: 269-275, doi: 10.1016/j.rmed. 2011.07.018

33. Chalimoniuk M, Wronski Z, Gilewski K, Stolecka A, Langford $A$. Does exercise training affect NO/GC/cGMP pathway in the brain? J Hum Kinet 2005; 13: 27-40.

34. Sousa AM, Prado WA. The dual effect of a nitric oxide donor in nociception. Brain Res 2001; 897: 9-19, doi: 10.1016/ S0006-8993(01)01995-3.

35. Chen $Q$, Xiao DS. Long-term aerobic exercise increases redox-active iron through nitric oxide in rat hippocampus. Nitric Oxide 2014; 36: 1-10, doi: 10.1016/j.niox.2013.10.009.

36. Lovick TA. Role of nitric oxide in medullary raphe-evoked inhibition of neuronal activity in the periaqueductal gray matter. Neuroscience 1996; 75: 1203-1209, doi: 10.1016/ 0306-4522(96)00325-9.

37. Hamalainen MM, Lovick TA. Involvement of nitric oxide and serotonin in modulation of antinociception and pressor responses evoked by stimulation in the dorsolateral region of the periaqueductal gray matter in the rat. Neuroscience 1997; 80: 821-827, doi: 10.1016/S0306-4522(97)00124-3.

38. Galeotti N, Ghelardini C, Vinci MC, Bartolini A. Role of potassium channels in the antinociception induced by agonists of alpha2-adrenoceptors. Br J Pharmacol 1999; 126: 1214-1220, doi: 10.1038/sj.bjp.0702395. 